Migchelbrink, K. \& Van de Walle, S. (accepted). When will officials listen? Experimental evidence on citizen participation and input legitimacy. Public Administration Review.

https://doi.org/10.1111/puar.13138

\title{
When Will Public Officials Listen? A Vignette Experiment on the Effects of Input Legitimacy on Public Officials' Willingness to Use Public
}

\section{Participation.}

\begin{abstract}
Public officials can be reluctant to use citizens' input in decision making, especially when turnout is low and when participants are unrepresentative of the wider population. Using Scharpf's democratic legitimacy approach, we conducted a survey-based vignette experiment to examine how the input legitimacy of participatory processes affects (1) public officials' willingness to use public participation in administrative decision-making, (2) their assessment of the quality of the policy decisions, and (3) their anticipation of the popular support for the policy outcome. Our study shows that turnout and participants' representativeness have a positive and significant effect on public officials' attitudes toward public participation. Specifically, we found that participants' representativeness influences public officials' willingness to use citizens' inputs more than turnout does.
\end{abstract}




\section{Practitioner Points}

- Public officials' attitudes toward public participation in administrative decisionmaking are partly dependent on the size of turnout and participants' representativeness.

- Public officials' are more positive about public participation when they assess turnout and participant representativeness to be high than when they assess turnout and participant representativeness to be low.

- Public officials' willingness to engage with the public is influenced more by participants' representativeness than by turnout.

- Public officials seem to operate under the default assumption that public participation is useful, that it improves the quality of decisions, and that it enhances the popular support for public policies 


\section{Introduction}

Public officials' positive attitudes toward public participation are important to the success of public engagement efforts (Liao and Schachter 2018; Yang and Callahan 2007). However, a lack of input legitimacy during participatory processes, for instance, when actual participation is low or when those who participate are not representative of the wider population, can make public officials reluctant to use citizens' input in the decision-making process. Public officials deplore what they see as the same handful of people participating on a regular basis (Yang and Callahan 2005, 2007), and may consider public participation without sufficient input legitimacy an unwanted burden (Irvin and Stansbury 2004; Kweit and Kweit 1981). Unless public officials assess the inputs of citizens to be sufficiently representative, they might not use those inputs at all.

Proponents of direct public participation argue that public participation is instrumental in increasing the quality and legitimacy of public administrations (e.g., Nabatchi, 2010; Yang, 2016), that it facilitates the identification of new ideas and solutions to societal challenges (Bryson et al. 2013; Nabatchi 2012; Thomas 1995; Thomas 2012), that it serves as a client feedback mechanism for public services (Campbell \& Lambright, 2016), and that it can foster community support for government programs and policies (Moynihan 2003; Ebdon and Franklin 2006; Yang 2016). On the other hand, opponents argue that public participation at best serves as yet another opportunity for the participatory elite (male, well-educated, affluent citizens) to press their advantages, and at worst that it is a waste of administrative resources, time, and money, resulting in suboptimal and biased policy outcomes (Verba et al. 1993; Neblo et al. 2010; Irvin and Stansbury 2004; John 2009).

Central to the success of participatory processes are public officials willing to engage with citizens (Ianniello et al. 2018; Yang 2006; Hong 2015; Hatcher 2015; Liao and 
Schachter 2018; Yang and Callahan 2007). Public officials are involved in all stages of the participatory process, influence how participation takes place, and how public inputs are put into practice (Neshkova and Guo 2018; Yang and Callahan 2007; Bryson et al. 2013; Buckwalter 2014). According to Yang and Callahan (2007), "it stands to reason that favourable attitudes toward public participation may positively affect administrative decisions to include citizens in administrative processes" (p. 250; also: Hong, 2015; Yang \& Callahan, 2007; Zhang \& Yang, 2009).

In this paper, we study how the input legitimacy of participatory processes affects public officials' attitudes toward public participation in administrative decision-making. Are public officials more willing to use citizens' inputs in administrative decision-making when these inputs come from a participatory process characterized by high turnout and representative participants instead of low turnout and unrepresentative participants? Do public officials believe that participatory processes with high input legitimacy produce qualitatively better policies and decisions than processes with low input legitimacy? Do public officials anticipate that turnout and participants' representativeness affect popular support for policies and decisions? In order to answer these questions, we formulate the following research question:

What is the effect of the input legitimacy of a participatory process on the attitudes of public officials toward public participation in administrative decision-making?

We addressed this research question using an online survey-based vignette experiment with 890 local government officials. These officials were randomly assigned to evaluate four short descriptions (vignettes) of an administrative decision-making process involving public 
participation. In these vignettes, respondents were presented with a public participation process characterized by low turnout and unrepresentative participants, low turnout and representative participants, high turnout and unrepresentative participants, high turnout and representative participants, or no information about turnout and participants' representativeness at all. After each vignette, respondents were asked to evaluate the vignette using questions designed to (1) assess their willingness to use public participation, (2) determine their assessment of the quality of the resulting policy decision, and (3) measure the extent to which they believed that the inclusion of citizens' input would increase the popular support for the decision.

We start by reviewing the literature on public officials' attitudes toward public participation in public administration. In the second section, we present our theoretical framework. We use Scharpf's $(2003,1970,1999)$ democratic legitimacy approach to explain how the input legitimacy of a participatory process affects public officials' attitudes toward public participation. We also formulate three hypotheses that guide the research. In the third section, we present our methodological approach, followed by the experiment's results in section four. In the final two sections of the paper, we discuss these results and present our conclusions.

\section{What determines officials' attitudes about public participation?}

Previous research demonstrates that public officials' attitudes toward public participation are an important element in the success of participatory decision-making efforts (Denhardt and Denhardt 2015; Liao and Schachter 2018; Neshkova and Guo 2018; Yang 2006; Zhang and Yang 2009; Hatcher 2015; Yang and Callahan 2007). However, research on the determinants of public officials' attitudes toward public participation is limited 
(exceptions e.g., Liao and Schachter 2017; Ianniello et al. 2018). Among the most studied determinants influencing public officials' attitudes toward public participation are its perceived costs (Irvin and Stansbury 2004; Liao and Schachter 2018; Moynihan 2003), the participatory competences of citizens (Yang and Pandey 2011; Yang and Callahan 2007; Hong 2015), and the democratic legitimacy of participatory processes (Pina and Torres 2016; Yang and Callahan 2005; Yang and Pandey 2011).

Previous research indicates that public officials assess the benefits of public participation in relation to its perceived costs (Sjoberg, Mellon, and Peixoto 2017; Liao and Schachter 2018; Moynihan 2003). "The per decision costs of citizen-participation [...] is arguably more expensive than the decision making of a single administrator" (Irvin and Stansbury 2004). For public officials to be willing to engage with citizens, the benefits must outweigh the costs. Moynihan distinguished four types of participation costs: direct administrative costs, self-interested administrative costs, decision process costs, and decision outcome costs. He argues that managers might reduce representativeness and citizens' influence in order to reduce administrative coordination costs and managers' self-interest costs (Moynihan 2003). Similarly, Liao and Schachter (2017) argue that public managers are more likely to support public participation when they believe participation contributes to policy development at low costs. They studied how sociohistorical, organizational, and individual factors affect perceptions of participatory costs and benefits. Their results show that managers' red tape perceptions and technocratic orientation increase the perception of participation cost, while knowledge of previous success factors increases perceived benefits. They conclude that the perceived costs and benefits of participation cannot be separated from the social context in which those attitudes were constructed (Liao and Schachter 2018). In addition, participation costs are also related to public officials' self-interest (Moynihan 2003). Administrative self-interest costs arise from public officials' potential loss of control and 
reduced administrative influence and autonomy over day-to-day activities. Public "officials tend to be jealous of their legal authority and are loath to share it with citizens" (Kweit and Kweit 1981, 96).

Public officials' attitudes toward public participation are also influenced by their perceptions of citizens’ participatory competences (King, Feltey, and Susel 1998; Hong 2015; Kweit and Kweit 1981; Thomas 1995; Yang and Callahan 2007; Yang and Pandey 2011). In general, "many public managers do not trust that citizens have the competence to participate effectively" (Yang and Pandey 2011). One study found that almost half of its respondents perceived a lack of citizens' expertise as a barrier to citizen involvement, affecting both the reported use of participation mechanisms and the reported use of public participation in strategic decision making (Yang and Callahan, 2007). In addition, public managers appear more positive about the outcomes of participatory processes involving citizens they perceive to be more competent (Yang and Pandey 2011; Hong 2015). Research finds that participants' knowledge and inclusiveness positively affect the number of proposals that are adopted. In this study, local city councilors were more inclined to adopt proposals from participants whom they perceived to have sufficient knowledge about the policy issue at hand and from processes with higher inclusivity (Hong 2015).

Other studies focus on the effect of the participatory quality of the participation process on public officials' attitudes toward public participation. According to these studies, public officials are less willing to use participatory inputs when only a small number of people participate or when those who participate are unrepresentative of the community they represent (Verba et al. 1993; King, Feltey, and Susel 1998; Yang and Pandey 2011; Pina and Torres 2016). Unless designers actively engage in the fair design of participatory processes, inequities will persist (Clark 2018; John 2009). Research established a direct link between participants' representativeness and public officials' attitudes toward public participation. 
Yang and Callahan (2005) found that $85 \%$ of the 248 county and municipal public officials they surveyed believed that "the same handful of people participated on a regular bases" (Yang and Callahan 2005). Two years later, the same authors concluded that "administrators tend to dismiss the input of usual suspects and perceive their regular involvement to be troublesome" (Yang and Callahan 2007).

In an interview study among German, Spanish, and Austrian public officials, Pina and Torres (2016) found that three quarters of respondents rated the representativeness of participants in public participation processes as moderate or insufficient. Furthermore, a quarter of respondents regarded the lack of representativeness as a serious barrier to participation, concluding that "it is always the same (already known) people who participate in the initiatives" (Pina and Torres 2016). Other research found that participant representativeness is directly related to participation outcomes (Yang and Pandey 2011). In a study of 1097 functional managers, Yang and Pandey (2011) concluded that "the more nonrepresentative the participation is, the less likely change will occur in government decision making" (p. 886).

These factors are but a few of the determinants of public officials' attitudes identified in the literature (also: Ianniello et al., 2018; Liao \& Schachter, 2017; Yang \& Pandey, 2011). This study focusses on the effect of the democratic legitimacy of the participatory process on public officials' participatory attitudes.

\section{Explaining Public Participation using Input Legitimacy}

Scharpf's $(2003,1970,1999)$ democratic legitimacy approach provides an explanation as to how turnout and participants' representativeness affect public officials' attitudes toward public participation. The democratic legitimacy approach is based on the normative premise 
that legitimate rulemaking should be based on the voices and interests of the community to which those rules apply (Scharpf, 2003).

Democratic legitimacy is a multifaceted concept. According to Scharpf $(1999,2003)$, it consists of two elements: input legitimacy and output legitimacy. Input legitimacy refers to the participatory quality of the decision-making process. It posits that rulemaking is legitimate when rules are derived from the authentic participation and preferences of the members of a community. It denotes the extent to which the decision-making process reflects citizens' opinions and attitudes. Output legitimacy states that rules are "legitimate if and because they effectively promote the common welfare of the constituency in question" (Scharpf 1999, 6). It refers to the effectiveness and problem-solving quality of the decisionmaking process. It denotes the measure to which policies are able to meet their predefined objectives and can be conceptualized as the quality of policies, popular support for policies, etc. (Schmidt 2013; Scharpf 1999, 2003). As such, input legitimacy and output legitimacy are two sides of the same coin; whereas input legitimacy is government by the people, output legitimacy is government for the people (Scharpf 1999).

Why does the legitimacy of a participatory process affect public officials' attitudes towards it? The main importance of legitimacy is behavioral. Tyler (2006) defined legitimacy as "the belief that authorities, institutions, and social arrangements are appropriate, proper and just" (Tyler 2006, 376). Actors such as public officials are more inclined to act in accordance with what they perceive is legitimate. For Scharpf, legitimacy beliefs imply "a socially sanctioned obligation to comply with government policies” (Scharpf 2003, 2). Therefore, as rulemaking and decision-making procedures are perceived to be more legitimate, decisions and rules are more willingly accepted (Tyler 2006). 
We argue that public officials' attitudes toward public participation are affected by their belief in the legitimacy of the participatory process. Higher turnout and representative participants increase the democratic input legitimacy of a participatory process and result in more favorable attitudes toward public participation. Therefore, higher input legitimacy could make public officials more willing to use citizens' inputs in administrative decision-making. We formulate the following hypothesis:

$H_{1}$ : The higher the input legitimacy of a participatory process, the more willing public officials are to use its citizen inputs in administrative decision-making.

The input legitimacy of a participatory process also affects public officials' perception of the output legitimacy of a participatory process. Bureaucracies are goal-oriented institutions in which public officials are expected to assess how policy inputs affect organizational performances and outputs (Downs 1967; Meier and O’Toole 2006; Moynihan 2003). As such, public officials will evaluate the benefits of public participation in instrumental terms (Neshkova and Guo 2012; Moynihan 2003).

The input legitimacy of a participatory process could affect public officials' perceptions of the extent to which public participation increases the quality of policies. For public officials, public participation can serve as a tool to identify and address new ideas and solutions to challenging problems (Fung 2006; Bryson et al. 2013; Nabatchi 2010; Thomas 1995) or to learn from citizens' experiences (Fischer 2009; Callahan 2007). Public participation can also help decision makers understand clients' needs and feedback (Vigoda 2002; Frederickson 1980; Zhang and Yang 2009; Moynihan 2003). However, it is unclear 
whether public officials will take inputs serious when they are produced by a small and unrepresentative group of participants.

Furthermore, the input legitimacy of a participatory process can also affect public officials' anticipation of popular support for policy outcomes. Procedural fairness theory demonstrates that citizens are more willing to accept rules and decisions they believe are established through fair and honest procedures (Tyler 2006). For example, Thibaut and Walker (1978) show that decision acceptance is linked to the fairness of the procedures by which authorities make those decisions. Additionally, prior research on participatory processes finds that participation fosters community support for programs and policies that organizations implement (Nabatchi and Amsler 2014; Moynihan 2003; Ebdon and Franklin 2006; Thomas 2012) and provides citizens with a sense of policy ownership (Wang 2001; Irvin and Stansbury 2004; Denhardt and Denhardt 2015). Based on these studies, we formulate two more hypotheses:

$\mathrm{H}_{2}$ : The higher the input legitimacy of a participatory process, the higher the anticipated quality its policy outcomes.

$H_{3}:$ The higher the input legitimacy of a participatory process, the higher the anticipated popular support for its policy outcomes.

\section{Method}

\section{Experimental Design}

We tested our hypotheses using a survey-based vignette experiment. A vignette is a "short, carefully constructed description of a person, object, or situation, representing a 
systematic combination of characteristics" (Atzmüller and Steiner 2010, 128) to which respondents are invited to respond (also: Jilke and Van Ryzin 2017). The systematic manipulation of the characteristics included in the vignettes provides the experimental treatment used to assess the effects under observation (Auspurg and Hinz 2015; Atzmüller and Steiner 2010). Vignette experiments combine the internal validity of experiments with the external validity of surveys (Gerber and Green 2012; Mutz 2011; Atzmüller and Steiner 2010; Auspurg and Hinz 2015) and are empirically relatively robust (Hainmueller, Hangertner, and Yamamoto 2015). Research indicates that vignette experiments are particularly well suited for testing the effects of personal attitudes, judgments, beliefs, norms, etc., on actual behavior (Aguinis and Bradley 2014; Finch 1987; Hughes and Huby 2004; Atzmüller and Steiner 2010; Jilke and Van Ryzin 2017).

Our experimental design included two characteristics (factors) manipulated at two levels (e.g., a 2*2 full-factorial design; Mee 2009). Unlike the classic one-factor experiment, the full-factorial design enables the simultaneous manipulation of multiple factors, leading to more valid and realistic experimental scenarios (Auspurg and Hinz 2015; Mee 2009; Atzmüller and Steiner 2010). The two factors included in this experiment were turnout and participants' representativeness. Turnout was operationalized as a contextualized measure of the number of participants participating in a participatory activity. The treatment combination indicated either high turnout (higher than expected) or low turnout (lower than expected). Participants' descriptive representativeness was operationalized as the extent to which a neighborhoods' socioeconomic and demographic characteristics were reflected by the participants participating in the participatory activity (e.g., Pitkin, 1967). The treatment combination indicated either high participant representativeness (a representative group of local residents) or low participant representativeness (a select group of active local residents). Additionally, we included a control vignette with 'no information shown' as control 
condition in which the sentences describing the turnout and representativeness of participants were omitted.

This design was replicated over two interchangeable and politically uncontroversial vignette scenarios ( $\mathrm{n}=10$ vignettes). The first scenario described citizens participating in a decision-making process about replacing bicycle parking spaces with public seating; the second scenario described citizens participating in a decision-making process on the construction of a neighborhood playground. Respondents were presented with a hypothetical colleague with the discretion to decide on the extent to which citizens' inputs were incorporated into a policy recommendation. We asked respondents to evaluate that colleague's decision as if it was their own decision to make, so that they used their own preferences in the evaluation of the vignette scenario. Previous research indicates that asking respondents to react to a hypothetical colleague (a third-person perspective) instead of reacting to the vignette scenario directly reduces the possibility of social desirability bias (Constant, Kiesler, and Sproull 1994; Hughes and Huby 2004; Finch 1987). The vignettes were presented to the respondents in their own vernacular. An English translation of the vignettes is presented in figure 1.

--- Insert figure 1 here ---

We used the vignettes to estimate the effects of turnout and participants' representativeness on three outcome variables: public officials' willingness to use citizens' inputs in administrative decision making (My policy recommendation would depend strongly on the input provided by the local residents), public officials' anticipation of policy quality (By including the input of these local residents, the quality of the recommendation will 
increase considerably), and public officials' anticipation of popular support (By including the input of these local residents, the acceptance of the policy recommendation's outcome by local residents will increase considerably). All three variables were measured on a sevenpoint Likert-like scale $(1=$ totally disagree, $7=$ totally agree $)$. The vignettes were assigned using a within-subjects design. We asked each respondent to evaluate four randomly assigned vignettes. We used a within-subjects design because the minimally required sample size could not be attained using a between-subjects design. ${ }^{1}$

Importantly, in a within-subjects design, vignette evaluations are clustered within respondents. This increases the risk of response biases, confounding effects, and carryover when not appropriately corrected. We reduced the possible pathological effects of the withinsubjects design in three ways. First, we randomized the assignment of vignettes to respondents (Gerber and Green 2012; Hainmueller, Hopkins, and Yamamoto 2014; Jilke and Van Ryzin 2017; Montgomery, Nyhan, and Torres 2018). Second, we employed response interruption questions to interrupt respondents' habituation and increase the temporal and proximal distance between similar questions (Podsakoff, MacKenzie, and Podsakoff 2012). Third, we clustered the standard errors because observations were not independent from each other. We estimated the respondents-clustered standard errors using the Fast Estimators for Design-Based Inference package in R (Blair et al. 2018). ${ }^{2}$

We pre-tested the vignette scenarios, treatment conditions, and the technical implementation of the experiments twice; once among a group of 21 public management $\mathrm{PhD}$ students and once among a subset of respondents $(n=9)$. The number of evaluations per vignette, ranging from $n=339$ to $n=374$ are included in appendix 1 .

\section{Sampling}


For this study, we sampled public officials working for Belgium's largest city: Antwerp. The city of Antwerp is a major urban center with a population of over 520.000 inhabitants and a professional staff of around 6900 employees in 2016 (City of Antwerp 2016). We focused on local public officials. Public officials and citizens interact most directly at a local level and local level policy issues are most comprehensible and applicable to citizens (building permits, neighborhood-zoning policies, etc.). Not surprisingly, most citizen involvement experiments and participatory innovations take place at the local level (Nabatchi and Amsler 2014).

The sampling frame contained apolitical career officials with administrative grade A or B, employed by the municipal administration. These officials have the analytical skills and theoretical knowledge required to run the administration and formulate policies. Their administrative grades are based on educational attainment. Public officials with an academic or vocational bachelor's degree are labeled administrative grade B. Public officials with an academic master's degree or higher are labeled administrative grade A (Flemish Government 2006). City of Antwerp officials facilitated access to the sampling frame and provided background data on the participants. The size of the sampling frame and the easy access to the respondents enabled us to follow a total sampling strategy. We purposefully included all administrative grade A and B public officials employed by the city in our study. The sampling frame contained $\mathrm{N}=2128$ individuals.

We administrated the study online, using the survey program Qualtrics. Every public official in the sampling frame received an invitation, informing them about the purpose and objective of the study and providing them with a unique link to the vignettes. To increase the response rate, we sent two reminder emails to nonrespondents, spaced one week apart. Access to the survey and vignette instrument was restricted to participants who provided their informed consent to participate. The survey took about fifteen minutes to complete. 


\section{Method of analysis}

We analyzed the results in two steps. First, we determined the vignette means for each vignette and assessed their relationships graphically. Second, we estimated the average treatment effects (ATEs) of turnout and participants' representativeness based on the playground scenario vignettes only (excluding the control vignette). For this second part of the analysis, we followed Mee's (2009) analytical recommendations and recoded the vignette manipulations into two orthogonal variables (one for turnout and one for participants' representativeness). Each factor's high-level manipulation was coded 1, and each factor's low-level manipulation was coded -1 . We subsequently ran a two-factor interaction model for a $2 * 2$ factorial design (Mee 2009) to estimate the ATEs. As stated above, to account for possible clustering due to the within-subjects sampling procedure, we estimated confidence intervals using respondents-based cluster-robust standard errors (Blair et al. 2018).

\section{Fielding}

The vignettes were fielded between February $1^{\text {st }}$ and February $21^{\text {st }}, 2018$. Of the 2128 individuals in the sampling frame, 1270 responded to the invitation. A total of $n=890$ participants completed the vignette experiments and were included in the analysis, which amounts to a response rate of $41.8 \%$. Except for a small age difference, the background characteristics of the 380 dropouts did not differ statistically from the final sample. ${ }^{3}$ One treatment combination was administered twice and was removed from the analysis (the high turnout / unrepresentative vignette in the seating scenario). Figure 2 displays the distributions (density plots) of the vignette assessments for both sets of vignettes per dependent variable. 
We assessed the randomization using four balance tests. The absence of statistically significant differences in the parameters of the overall sample compared to the individual vignette samples indicates balance and successful randomization. Apart from a small oversampling of women in the first control vignette, no statistically significant differences between the vignette populations and the overall population were observed. ${ }^{4}$ The sample contained 512 women and 366 men. Of them, 514 had administrative grade A and 367 had administrative grade B. The mean sample age of 42.1 years old, was slightly higher than the mean population age of 41.2 years. $^{5}$

\section{Results}

Does the input legitimacy of the participatory process affect public officials' willingness to use citizens' inputs in decision-making, their perception of policy quality, and their anticipation of popular support for the policy outcome? Figure 3 presents the vignette means per treatment combination for the three outcomes: respondents' willingness to engage, perceptions of outcome quality, and their anticipation of popular support. The results indicate that the turnout and representativeness of participants affect public officials' ${ }^{\prime}$ attitudes toward public participation, providing support for our three hypotheses. 
For most treatment combinations, the mean vignette score indicates that officials are positive about public participation in administrative decision-making. The vignette means are highest for the treatment combinations 'high turnout and representative participants', indicating that officials' are most positive about public participation when these two conditions are high. Only in the treatment combinations where turnout was low and where participants were unrepresentative did the vignette means drop below the center of the scale, indicating officials' relative unwillingness to use the inputs of such participatory processes. Similarly, respondents did not assess participatory processes with low turnout and unrepresentative participants to result in high quality inputs or to foster much public support. Interestingly, respondents rated the control vignettes without information about turnout and participants' representativeness higher than the vignettes with either high turnout and unrepresentative participants or low turnout and representative participants. A full list of vignette means is included in appendix 2.

\section{Turnout and participant representativeness}

Table 1 presents the average treatment effects (ATEs) of turnout and participants' representativeness on public officials' attitudes toward public participation based on the playground scenario. The ATEs' standard errors are included between brackets.

--- Insert table 1 here ---

Table 1 shows that turnout and participants' representativeness influence officials' willingness to use citizens' inputs in administrative decision-making. Of both factors, 
participants' representativeness has a larger impact than turnout does. The Cohen's D effect sizes indicate that the effects of turnout and participants' representativeness on respondents' willingness to include citizens' inputs in administrative decision-making are moderate. Turnout and participants' representativeness also affect respondents' perceptions of participation-based input quality. The ATEs of both factors on officials' perceptions of quality are roughly the same, with the effect of turnout $(\mathrm{d}=.321)$ marginally larger than that of participants' representativeness $(\mathrm{d}=.305)$. Finally, we found that both turnout and participants' representativeness affect respondents' anticipation of popular support for policy outcomes as well. Again, the ATEs for turnout and participants' representativeness are moderate and about equal in size. For all three outcomes, we found no evidence for a statistically significant interaction effect between turnout and participants' representativeness.

\section{Discussion}

Previous research established public officials' attitudes toward public participation as one of the determining factors shaping the success of public participation practices (Kweit and Kweit 1981; Hatcher 2015; Yang and Callahan 2007; Liao and Schachter 2018; Denhardt and Denhardt 2015; Buckwalter 2014). Importantly, studies into the determinants of public officials' attitudes toward public participation are largely absent (notable exceptions include: Liao \& Schachter 2017; Yang \& Callahan 2007). This study builds on previous research by further exploring the determinants of public officials' attitudes toward public participation (in terms of their willingness to use citizens' inputs, their perceptions of policy quality, and their anticipation of popular support) by examining the effects of the input legitimacy of participatory processes. It provides empirical support to research establishing a link between 
the input legitimacy of participatory processes and public officials' attitudes toward public participation (e.g., Pina \& Torres, 2016; Yang \& Callahan, 2005, 2007).

Our study indicates that public officials' attitudes toward public participation in administrative decision-making are not predetermined but, at least in part, contingent on the practical implementation of the participatory process itself. Public officials are significantly more positive about participatory processes with high turnout and representative participants than about participatory processes with low turnout and unrepresentative participants. Public officials are also more positive about the quality of its policy outputs and anticipate those processes to foster more popular support. At the same time, public officials appear to be less willing to engage with citizens, assess the quality of participation-based policies lower, and perceive the popular support for outcomes to be lower when input legitimacy is low.

Other studies have pointed to the importance of public officials' attitudes in shaping the participation process as well (Buckwalter 2014). Various characteristics of the participatory process are determined or influenced by public officials (e.g., the number of meetings, the length of deliberation, the venue). Institutionally, officials both actively influence, and passively react to, the input legitimacy of a participatory process. Future research could help disentangle how public officials' roles before and during the participatory process influence their attitudes afterward.

Interestingly, the inclusion of two control vignettes revealed that public officials were more positive about the vignettes without information on the input legitimacy of a participatory process than when either or both turnout and participants' representativeness were low. This could indicate that officials operate under the default assumption that public participation is useful, that it improves the quality of decisions, and that it enhances the popular support for public policies (see also: Liao and Schachter 2017). A similar observation 
was made in a recent conjoint experiment on citizens' legitimacy perceptions of EUaccession referenda (Arnesen et al. 2019). In this study, the effects of turnout, the size of the majority, and the substantive outcome of the referendum on citizens' willingness to accept referenda outcomes were examined. Arnesen argued that citizens have a "perceptual bias" regarding referenda, indicating that citizens default attitudes about referenda are positive, irrespective of its characteristics (Arnesen et al. 2019, 16). In our study as well, respondents rated the control conditions second highest, just below the most positive treatment condition. Future research could extend these findings beyond topics related to public participation and referenda and explore how default perceptions influence public officials' stated preferences and actual behavior in administrative decision-making.

We further observed that the effects of specific input legitimacy dimensions (turnout, participants' representativeness) on public officials' attitudes toward public participation differ depending on the attitudes under observation. Participants' representativeness had a stronger effect on officials' willingness to engage with the public than turnout did. The effects of turnout and participants' representativeness on public officials' perception of participation-based policy quality and anticipated popular support are of roughly the same size. Clearly, the input legitimacy of a participatory process influences different attitudes differently.

This study has some limitations. The first limitation, well known in experimental research, relates to external validity. Our study was conducted among administrative grade A and B public officials at the administration of one city. Findings valid for this case are not automatically valid for other cases as well. Though there are no reasons to suggest that public officials working for the administration of the city of Antwerp have markedly different attitudes toward public participation than public officials working for any other comparable 
city administration, replications of this study at other municipalities (in other countries) could serve to strengthen the external validity of the observed effects.

Second, due to the limited number of available respondents, we used a within-subjects design and asked respondent to evaluate multiple vignettes. Though this strategy allowed us to maintain statistical power, it also increased the risk of habituation, carryover, and sensitizing biases (Charness, Gneezy, and Kuhn 2012). We controlled for possible carryover and order effects through the random assignment of vignettes to respondents, the increase of spatial and temporal distance between vignette assessments using a response interruption survey, and by using cluster robust standard errors in the estimation of the ATEs. Even though we found no evidence suggesting that the between-subjects allocation of vignettes caused bias, replicating this study using a between-subjects allocation design could strengthen the robustness of our results. In addition, due to a duplicate treatment in the seating scenario, the estimation of the ATEs of turnout and participants' representativeness was based on the playground scenario vignettes only.

A third limitation is the two-variable character of this study. The experimental nature of the research design allowed us to include only a limited number of variables (Auspurg and Hinz 2015; Mee 2009). Though randomization controlled for confounding factors, many other variables could also influence public officials' attitudes toward public participation. Of special interest for further research are questions related to public officials' expectations of the participatory competences of citizens, bureaucratic structures and red tape, and the influence of 'the political domain' on public officials' attitudes toward public participation. Further research into these and other possible determinants of public officials' attitudes toward public participation is needed. 
In this experiment, turnout was operationalized in subject-dependent terms. Respondents evaluated cases of public participation which either produced far fewer or far more reactions than expected (excluding the control vignettes). With this operationalization, we acknowledge that perceptions of what constitutes high or low turnout are grounded in the individual public official's frame of reference. Our findings are limited to these treatment conditions; other operationalizations could produce different results. Research replicating this experiment using a different operationalization can be an interesting new avenue for research as well.

\section{Conclusion}

In conclusion, what is the effect of the input legitimacy of a participatory process on the attitudes of public officials toward public participation? First, we found that public officials are more willing to use citizens' inputs characterized by high turnout and representative participation than by low turnout and unrepresentative participation (corroborating $\mathrm{H}_{1}$ ). Second, we found that public officials expect the policy outcomes of participatory processes characterized by high input legitimacy to be of higher quality than the policy outcomes of participatory processes characterized by low input legitimacy (corroborating $\mathrm{H}_{2}$ ). Third, the study showed that public officials anticipate the popular support for policies and decisions based on public participation to be higher when input legitimacy is high than when input legitimacy is low (corroborating $\mathrm{H}_{3}$ ).

Two additional results are of particular interest. First, we found that public officials were more positive about public participation when they had no information about the input legitimacy of a participatory process than when one or both dimensions of input legitimacy is (are) low. Second, we found that turnout and participants' representativeness influence 
different attitudes differently. Whereas participants' representativeness affects public officials' willingness to engage with citizens more than turnout does, both turnout and participants' representativeness have a comparable effect on public officials' perceptions of policy quality and anticipated popular support.

The input legitimacy of a participatory process plays an important role in shaping public officials' attitudes toward public participation. To stimulate positive attitudes toward public participation among public officials, and thereby facilitate genuine and meaningful participation, it is important to pay attention to turnout and participants' representativeness in participatory processes. 


\section{Endnotes}

${ }^{1}$ We determined the minimal sample size required using a power analysis in the Basic Functions for Power Analysis package in the software program R (Champely et al. 2017). Using a previously obtained effect size of citizen representativeness on public officials' attitudes toward public participation of .08 as reference (Yang and Pandey 2011), we determined that we needed at least $\mathrm{n}=440$ individuals per vignette in order to reject the null hypotheses at a .05 significance value at least $80 \%$ of the time (rough total of $n=2200$ observations). The need for such a large group of respondents informed the design of the experiment and the choice for a within-subjects design.

${ }^{2}$ We applied a two-stage randomization design. First, we randomly assigned the vignettes into two blocks. Second, respondents were each assigned two out of the five vignettes per block to evaluate. In the first block, respondents were randomly assigned to two of the vignettes $2,4,5,9$, and 10 , and in block two, respondents were randomly assigned to two of the vignettes $1,3,6,7$, and 8 . The two blocks were separated by a set of response-interruption questions, unrelated to the experiment.

${ }^{3}$ To test for significant differences between the dropouts and the final sample we conducted three Pearson's chi-squared tests of the independence of gender $\left(\chi^{2}=2.36\right.$, df. $\left.2, \mathrm{p}=.307\right)$, administrative grade $\left(\chi^{2}=.159\right.$, df. $\left.1, \mathrm{p}=.690\right)$, and work domain $\left(\chi^{2}=40.26\right.$, df. $42, \mathrm{p}=$ .547). All were highly insignificant. For these variables, we reject independence and conclude that there is no evidence for significant group differences. This was not the case for the age distribution. The Wilcoxon signed-rank test, testing whether the dropout and final sample age were identical, was highly significant $(\mathrm{V}=44720, \mathrm{p}<.001)$. Young people dropped-out relatively more than old people (relative to the mean age). 
${ }^{4}$ The four balance tests were similar to the dropout tests: $3 \chi^{2}$ tests of independence and a Wilcoxon signed-rank test. We used the $\chi^{2}$ tests of independence to test for significant proportional differences between the overall sample and the vignette samples regarding gender, administrative grade, and policy domains. All the tests produced insignificant results (ps > .05). We used the Wilcoxon signed-rank test to test for a difference in the age distribution. Except for a significant difference regarding the control vignette (seating; $\chi^{2}=$ $6.92, \mathrm{p}$-value $=.009 ;$ oversampling of women $),$ no significant differences were observed $(\mathrm{p}>$ $.05)$.

${ }^{5}$ Additionally, we assessed the validity of the experimental treatments using three instructional manipulation checks and one check for speeders. Respondents were asked whether one of the vignettes they evaluated contained information about respondents' age, political conviction, or educational attainment. Our results are robust against excluding respondents who answered more than one of these questions incorrectly and who had a mean response time per vignette of less than 25 seconds $(n=65)$. 


\section{References}

Aguinis, Herman, and Kyle J. Bradley. 2014. "Best Practice Recommendations for Designing and Implementing Experimental Vignette Methodology Studies.” Organizational Research Methods 17 (4): 351-71. doi:10.1177/1094428114547952.

Arnesen, Sveinung, Troy Saghaug Broderstad, Mikael Poul Johannesson, and Jonas Linde. 2019. “Conditional Legitimacy: How Turnout, Majority Size and Outcome Affect Perceptions of Legitimacy in EU Membership Referendums.” doi:10.1177/1465116518820163.

Atzmüller, Christiane, and Peter M. Steiner. 2010. "Experimental Vignette Studies in Survey Research.” Methodology 6 (3): 128-38. doi:10.1027/1614-2241/a000014.

Auspurg, Katrin, and Thomas Hinz. 2015. Factorial Survey Experiments. 2455 Teller Road, Thousand Oaks California 91320 United States: SAGE Publications, Inc. doi:10.4135/9781483398075.

Blair, Graeme, Jasper Cooper, Alexander Coppock, Macartan Humphreys, Luke Sonnet, and Neal Fultz. 2018. "Fast Estimators for Design-Based Inference."

Bryson, John M., Kathryn S. Quick, Carissa Schively Slotterback, and Barbara C. Crosby. 2013. "Designing Public Participation Processes.” Public Administration Review 73 (1): 23-34. doi:10.1111/j.1540-6210.2012.02678.x.

Buckwalter, N.D. 2014. “The Potential for Public Empowerment through GovernmentOrganized-Participation.” Public Administration Review 74 (5): 573-84. doi:10.1111/puar.12217.This.

Callahan, Kathe. 2007. "Citizen Participation: Models and Methods.” International Journal of Public Administration 30 (11): 1179-96. doi:10.1080/01900690701225366. 
Campbell, David A., and Kristina T. Lambright. 2016. "Program Performance and Multiple Constituency Theory." Nonprofit and Voluntary Sector Quarterly 45 (1): 150-71. doi:10.1177/0899764014564578.

Champely, Stephane, Claus Ekstrom, Peter Dalgaard, Jeffrey Gill, Stephan Weibelzahl, Clay Ford, and Robert Volcic. 2017. "Package 'Pwr': Basic Functions for Power Analysis.” https://github.com/heliosdrm/pwr.

Charness, Gary, Uri Gneezy, and Michael A. Kuhn. 2012. "Experimental Methods: BetweenSubject and within Subject Design.” Journal of Economic Behavior and Organization 81: $1-8$.

City of Antwerp. 2016. "Personeelsbezetting Stad Antwerpen."

Clark, Jill K. 2018. "Designing Public Participation: Managing Problem Settings and Social Equity." Public Administration Review 78 (3): 362-74. doi:10.1111/puar.12872.

Constant, David, Sara Kiesler, and Lee Sproull. 1994. "What's Mine Is Ours, or Is It? A Study of Attitudes about Information Sharing.” Information Systems Research 5 (4): 400-421. doi:10.1287/isre.5.4.400.

Denhardt, Janet V, and Robert B Denhardt. 2015. “The New Public Service Revisited.” Public Administration Review 75 (5): 664-72. doi:10.1111/puar.12347.

Downs, Anthony. 1967. Inside Bureaucracy. Boston: Little Brown.

Ebdon, Carol, and Aimee L Franklin. 2006. "Citizen Participation in Budgeting Theory." Public Administration Review 66 (3): 437-47. doi:10.1111/j.1540-6210.2006.00600.x.

Finch, Janet. 1987. "Research Note: The Vignette Technique in Survey Research.” Sociology 21 (1): 105-14. 
Fischer, Frank. 2009. Democracy and Experise: Reorienting Policy Inquiry. New York: Oxford University Press.

Flemish Government. 2006. "Flemish Personnel Statute (VPS).” Belgium: Flemish Government. https://overheid.vlaanderen.be/vps.

Frederickson, George H. 1980. New Public Administration. Tuscaloosa: University of Alabama Press.

Fung, Archon. 2006. "Varieties of Participation in Complex Governance." Public Administration Review 66 (s1): 66-75. doi:10.1111/j.1540-6210.2006.00667.x.

Gerber, Alan S., and Donald P. Green. 2012. Field Experiments. Design, Analysis, and Interpretation. New York: W.W. Norton \& Company, Inc.

Hainmueller, Jens, Dominik Hangertner, and Teppei Yamamoto. 2015. "Validating Vignette and Conjoint Survey Experiments against Real World Behavior.” Proceedings of the National Academy of Sciences 112 (8): 2395-2400.

Hainmueller, Jens, Daniel J. Hopkins, and Teppei Yamamoto. 2014. "Causal Inference in Conjoint Analysis: Understanding Multidimensional Choices via Stated Preference Experiments.” Political Analysis 22 (1). Cambridge University Press: 1-30. doi:10.1093/pan/mpt024.

Hatcher, William. 2015. "The Effect of Public Participation in Municipal Budgeting: An Exploratory Survey of Officials in Government Finance Officers Association's AwardWinning Cities.” Public Administration Quarterly 39 (4): 645-63. https://searchproquest-com.kuleuven.ezproxy.kuleuven.be/docview/1770073265?accountid=17215.

Hong, Sounman. 2015. "Citizen Participation in Budgeting: A Trade-Off between Knowledge and Inclusiveness?" Public Administration Review 75 (4): 572-82. 
doi:10.1111/puar.12377.

Hughes, Rhidian, and Meg Huby. 2004. "The Construction and Interpretation of Vignettes in Social Research.” Social Work and Social Sciences Review 11 (1): 36-51. doi:10.1921/17466105.11.1.36.

Ianniello, Mario, Silvia Iacuzzi, Paolo Fedele, Luca Brusati, S. Lacuzzi, Paolo Fedele, and Luca Brusati. 2018. “Obstacles and Solutions on the Ladder of Citizen Participation: A Systematic Review.” Public Management Review 00 (00). Routledge: 1-26. doi:10.1080/14719037.2018.1438499.

Irvin, Renee A., and John Stansbury. 2004. "Citizen Participation in Decision Making: Is It Worth the Effort?" Public Administration Review 64 (1): 55-65. doi:10.1111/j.15406210.2004.00346.x.

Jilke, Sebastian R., and Gregg G. Van Ryzin. 2017. "Survey Experiments for Public Management Research.” In Experiments in Public Management Research, edited by Oliver James, Sebastian R. Jilke, and Gregg G. Van Ryzin, 117-38. Cambridge: Cambridge University Press. doi:10.1017/9781316676912.007.

John, Peter. 2009. "Can Citizen Governance Redress the Representative Bias of Political Participation?" Public Administration Review 69 (3): 494-503. doi:10.1111/j.15406210.2009.01995.x.

King, Cheryl Simrell, Kathryn M. Feltey, and Bridget O’Neill Susel. 1998. “The Question of Participation: Toward Authentic Public Participation in Public Administration.” Public Administration Review 58 (4): 317. doi:10.2307/977561.

Kweit, Mary G., and Robert W. Kweit. 1981. Implementing Citizen Participation in a Bureaucratic Society: A Contingency Approach. New York: Preager Publishers. 
Liao, Yuguo, and Hindy L. Schachter. 2018. "Exploring the Antecedents of Municipal Managers' Attitudes towards Citizen Participation.” Public Management Review 20 (9). Routledge: 1287-1308. doi:10.1080/14719037.2017.1363903.

Mee, Robert W. 2009. A Comprehensive Guide to Factorial Two-Level Experimentation. New York, NY: Springer New York. doi:10.1007/b105081.

Meier, Kenneth J, and Laurence J. O’Toole. 2006. "Political Control versus Bureaucratic Values: Reframing the Debate." Public Administration Review 66 (2): 177-92. doi:10.1111/j.1540-6210.2006.00571.x.

Montgomery, Jacob M., Brendan Nyhan, and Michelle Torres. 2018. "How Conditioning on Posttreatment Variables Can Ruin Your Experiment and What to Do about It.” American Journal of Political Science 62 (3): 760-75. doi:10.1111/ajps.12357.

Moynihan, Donald P. 2003. "Normative and Instrumental Perspectives on Public Participation: Citizens Summits in Washington D.C." The American Review of Public Administration 40 (2): 164-88. doi:10.1177/0275074003251379.

Mutz, Diana. 2011. Population-Based Survey Experiments. Princeton: Princeton University Press.

Nabatchi, Tina. 2010. “Addressing the Citizenship and Democratic Deficits: The Potential of Deliberative Democracy for Public Administration." The American Review of Public Administration 40 (4): 376-99. doi:10.1177/0275074009356467.

_ 2012. 'Putting the 'Public' Back in Public Values Research: Designing Participation to Identify and Respond to Values.” Public Administration Review 72 (5): 699-708. doi:10.1111/j.1540-6210.2012.02544.x.

Nabatchi, Tina, and Lisa Blomgren Amsler. 2014. "Direct Public Engagement in Local 
Government." The American Review of Public Administration 44 (4_suppl): 63S-88S. doi:10.1177/0275074013519702.

Neblo, Michael A., Kevin M. Esterling, Ryan P. Kennedy, David M.J. Lazer, and Amand E. Sokhey. 2010. "Who Want to Deliberate - And Why?" American Political Science Review 104 (3): 566-83.

Neshkova, Milena I., and Hai D. Guo. 2012. "Public Participation and Organizational Performance: Evidence from State Agencies.” Journal of Public Administration Research and Theory 22 (2): 267-88. doi:10.1093/jopart/mur038.

Neshkova, Milena I., and Hai David (David) Guo. 2018. "Policy Target Populations and Public Participation in Agency Decision Making.” International Public Management Journal 21 (2). Taylor \& Francis: 297-325. doi:10.1080/10967494.2016.1160012.

Pina, Vincente Vicente, and Lourdes Torres. 2016. “The Managers' View of Participation Processes with Citizen Panels.” In Evaluating E-Participation: Frameworks, Practices, Evidence, edited by and L Torres G. Aichholzer, H. Kubicek, 289-305. Basel: Springer, Cham. doi:10.1007/978-3-319-25403-6_14.

Pitkin, Hannah F. 1967. The Concept of Representation. Berkley: University of California Press.

Podsakoff, Philip M., Scott B. MacKenzie, and Nathan Podsakoff. 2012. "Sources of Method Bias in Social Science Research and Recommendations on How to Control It." Ssrn. doi:10.1146/annurev-psych-120710-100452.

Scharpf, Fritz W. 1970. Democratietheorie Zwischen Utopie Und Anpassung. Konstanz: Universitätsverlag. 1999. Governing in Europe: Effective and Democratic? New York: Oxford 
University Press.

—. 2003. "Problem-Solving Effectiveness and Democratic Accountability in the EU." MPifG. Vol. 03.

Schmidt, Vivien A. 2013. "Democracy and Legitimacy in the European Union Revisited: Input, Output and 'Throughput."” Political Studies 61 (1): 2-22. doi:10.1111/j.14679248.2012.00962.x.

Sjoberg, F.M. Fredrik M. F.M., Jonathan Mellon, and Tiago Peixoto. 2017. "The Effect of Bureaucratic Responsiveness on Citizen Participation.” Public Administration Review 77 (3): 340-51. doi:10.1111/puar.12697.

Thibaut, John, and Laurens Walker. 1978. “A Theory of Procedure.” California Law Review 66 (3): 541. doi:10.2307/3480099.

Thomas, John C. 1995. Public Participation in Public Decisions: New Skills and Strategies for Public Manager. Edited by Jossey-Bas. San Francisco: Jossey-Bass.

—. 2012. Citizen, Customer, Partner; Engaging the Public in Public Management. New York: E.M. Sharpe.

Tyler, Tom R. 2006. "Psychological Perspectives on Legitimacy and Legitimation.” Annual Review of Psychology 57 (1): 375-400. doi:10.1146/annurev.psych.57.102904.190038.

Verba, Sidney, Kay Lehman Schlozman, Henry Brady, and N.H Norman H. Nie. 1993. "Citizen Activity: Who Participates? What Do They Say?.” American Political Science Review 87 (02): 303-18. doi:10.2307/2939042.

Vigoda, Eran. 2002. "From Responsiveness to Collaboration: Governance, Citizens, and the Next Generation of Public Administration.” Public Administration Review 62 (5): $527-$ 40. doi:10.1111/1540-6210.00235. 
Wang, Xiaohu. 2001. “Assessing Public Participation in U.S. Cities.” Public Performance \& Management Review 24 (4): 322. doi:10.2307/3381222.

Yang, Kaifeng. 2006. “Trust in Citizen Involvement Decisions.” Administration \& Society 35 (5): 573-95.

. 2016. "Creating Public Value and Institutional Innovations across Boundaries: An Integrative Process of Participation, Legitimation, and Implementation.” Public Administration Review 76 (6): 873-85. doi:10.1111/puar.12561.

Yang, Kaifeng, and Kathe Callahan. 2005. “Assessing Citizen Involvement Efforts By Local Governments.” Public Performance \& Management Review 29 (2): 191-216. doi:10.1029/2008WR007042.

—. 2007. "Citizen Involvement Efforts and Bureaucratic Responsiveness: Participatory Values, Stakeholder Pressures, and Administrative Practicality." Public Administration Review 67 (2): 249-64. doi:10.1111/j.1540-6210.2007.00711.x.

Yang, Kaifeng, and Sanjay K. Pandey. 2011. "Further Dissecting the Black Box of Citizen Participation: When Does Citizen Involvement Lead to Good Outcomes?” Public Administration Review 71 (6): 880-92. doi:10.1111/j.1540-6210.2011.02417.x.

Zhang, Yahong, and Kaifeng Yang. 2009. "Citizen Participation in the Budget Process: The Effect of City Managers.” Journal of Public Budgeting, Accounting \& Financial Management 21 (2): 289-317. doi:10.1108/JPBAFM-21-02-2009-B006. 


\section{Appendix 1}

Table 1. Number of evaluations per vignette

\begin{tabular}{lc}
\hline Vignettes & n \\
\hline Seating: Control & 349 \\
Seating: Low turnout \& Unrepresentative participation & 374 \\
Seating: Low turnout \& Representative participation & 363 \\
Seating: High turnout \& Unrepresentative participation & 346 \\
Seating: High turnout \& Representative participation & 353 \\
Playground: Control & 351 \\
Playground: Low turnout \& Unrepresentative participation & 341 \\
Playground: Low turnout \& Representative participation & 376 \\
Playground: High turnout \& Unrepresentative participation & 339 \\
Playground: High turnout \& Representative participation & 368 \\
\hline
\end{tabular}




\section{Appendix 2}

Table 2. Vignette means (standard deviation between brackets)

\begin{tabular}{|c|c|c|c|}
\hline Vignettes & $\begin{array}{c}\text { Willingness to } \\
\text { engage }\end{array}$ & $\begin{array}{l}\text { Perception } \\
\text { of quality }\end{array}$ & $\begin{array}{c}\text { Anticipation } \\
\text { of popular } \\
\text { support }\end{array}$ \\
\hline Seating: Control & $4,533(1,240)$ & $4,659(1,235)$ & $4,782(1.240)$ \\
\hline $\begin{array}{l}\text { Seating: Low Turnout / Unrepresentative } \\
\text { participants }\end{array}$ & $3,634(1,296)$ & $3,890(1,327)$ & $4,032(1,395)$ \\
\hline $\begin{array}{l}\text { Seating: Low Turnout / Representative } \\
\text { participants }\end{array}$ & $4,278(1,295)$ & $4,510(1,249)$ & $4,548(1,268)$ \\
\hline $\begin{array}{l}\text { Seating: High Turnout / Representative } \\
\text { participants }\end{array}$ & $5,102(1,216)$ & $5,184(1,231)$ & $5,518(1,108)$ \\
\hline Playground: Control & $4,801(1,136)$ & $4,892(1,087)$ & $5,037(1,062)$ \\
\hline $\begin{array}{l}\text { Playground: Low turnout / Unrepresentative } \\
\text { participants }\end{array}$ & $3,455(1,261)$ & $3,745(1,291)$ & $3,777(1,332)$ \\
\hline $\begin{array}{l}\text { Playground: Low turnout/ Representative } \\
\text { participants }\end{array}$ & $4,434(1,253)$ & $4,564(1,216)$ & $4,620(1,225)$ \\
\hline $\begin{array}{l}\text { Playground: High turnout / Unrepresentative } \\
\text { participants }\end{array}$ & $4,183(1,370)$ & $4,602(1,261)$ & $4,667(1,356)$ \\
\hline $\begin{array}{l}\text { Playground: High turnout / Representative } \\
\text { participants }\end{array}$ & $5,182(1,081)$ & $5,250(1,040)$ & $5,486(1,105)$ \\
\hline Seating: Control & $4,403(1,360)$ & $4,589(1,309)$ & $4,720(1,353)$ \\
\hline
\end{tabular}


Figure 1 - the two base vignettes

\section{Imagine the following situation:}

A colleague of yours - an employee of the city of Antwerp - was asked to prepare a policy recommendation about replacing a number of bicycle stands with public seating and park benches.

City residents increasingly use bicycles to get to and from work and shops. Storing these bikes requires the use of a great deal of sparsely available space in the city center. At the same time, there is great need for more public seats and park benches to relax and meet friends and family. Replacing a number of bicycle stands with public seats is a solution, but it comes at the expense of scarce space to store bicycles. To solve this dilemma, local residents were invited to provide their opinion about the desirability of replacing a number of bicycle stands with public seating and park benches.

The participation activity produced $<$ far fewer / many more $>$ reactions than expected. These reactions mainly came from <a select group of active local residents / a representative group of local residents $>$. Based on this information, your colleague had to decide how important the information provided by the local residents was going to be in the final policy recommendation.

\section{Imagine the following situation:}

A colleague of yours - an employee of the city of Antwerp - is asked to prepare a policy recommendation about the construction of a neighborhood playground.

The construction of a neighborhood playground is expected to increase the quality of life in the neighborhood and increase the attractiveness for families with young children. At the same time, it is expected that the playground will increase noise disturbance and deplete funds for other community projects. To resolve this dilemma, local residents were invited to provide their opinion about the desirability of constructing a new playground.

The participation activity produced < far fewer / many more > reactions than expected. These reactions mainly came from <a select group of active local residents / a representative group of local residents $>$. Based on this information, your colleague had to decide how important the information provided by the local residents was going to be in the final policy recommendation. 
Figure 2 - density plots with normality line for each dependent variable
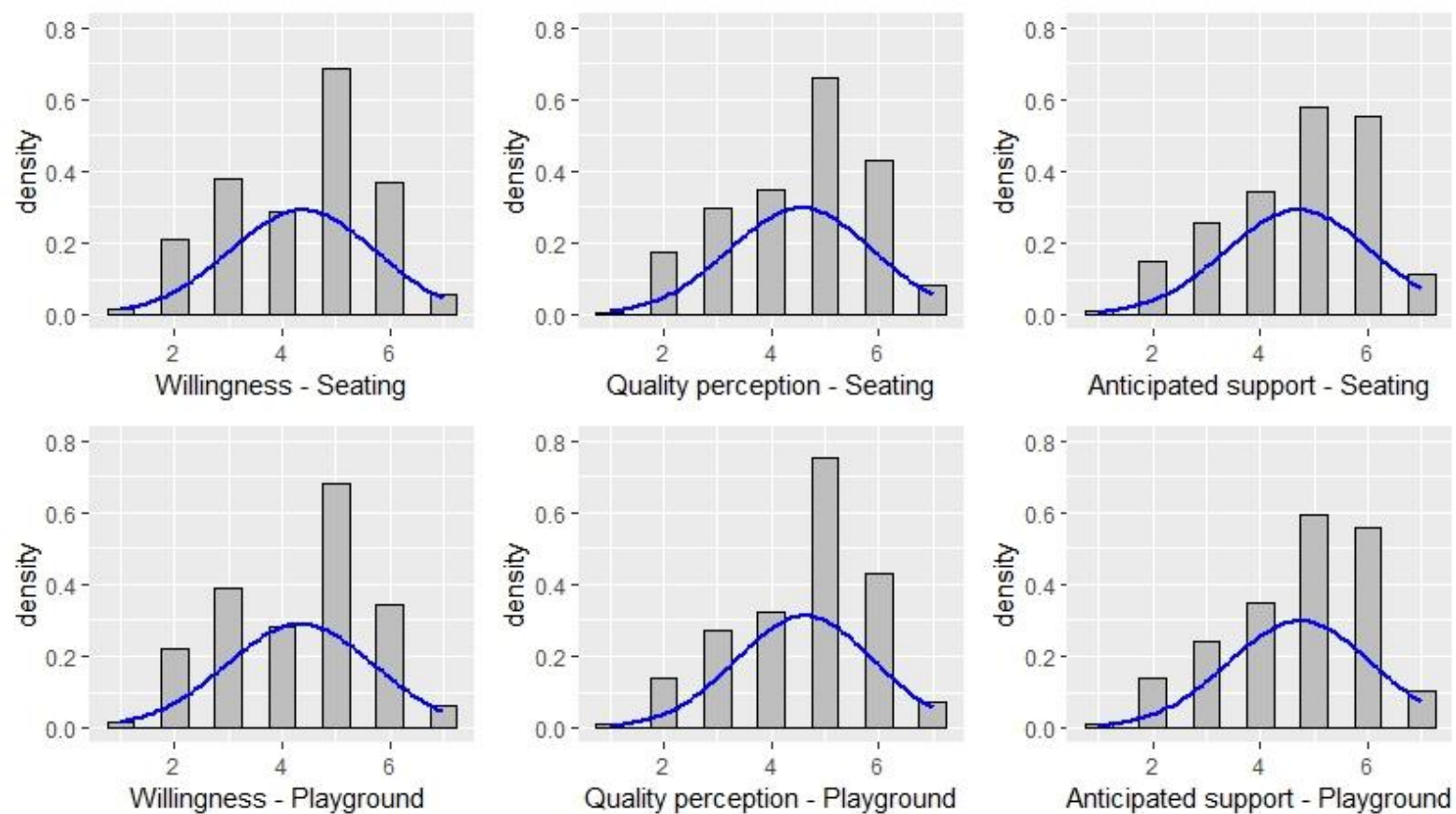

Figure 2. Density plots with normality line for each dependent variable 
Figure 3 - Treatment combinations (vignette means with their standard deviations)

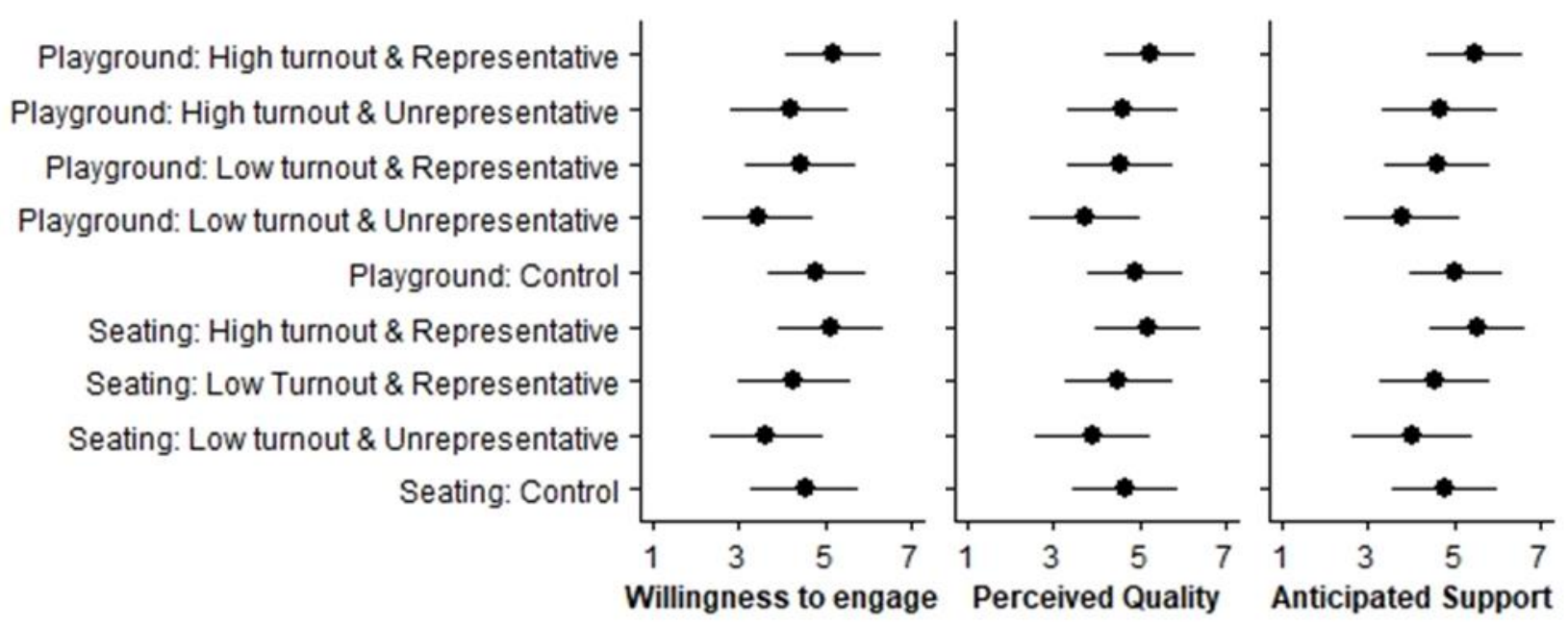

Figure 3. Treatment Combination Means (Vignette means within their standard deviation) 
Table 1 - ATEs of turnout and participants representativeness (Playground scenario)

Table 3. ATEs of turnout and participants representativeness (Playground scenario)

\begin{tabular}{|c|c|c|c|c|c|c|}
\hline & \multicolumn{2}{|c|}{$\begin{array}{c}\text { Willingness to } \\
\text { engage }\end{array}$} & \multicolumn{2}{|c|}{$\begin{array}{l}\text { Perception of } \\
\text { quality }\end{array}$} & \multicolumn{2}{|c|}{$\begin{array}{l}\text { Anticipation of } \\
\text { popular support }\end{array}$} \\
\hline & Estimate & $\begin{array}{l}\text { Cohen's } \\
D\end{array}$ & Estimate & $\begin{array}{c}\text { Cohen's } \\
D\end{array}$ & Estimate & $\begin{array}{c}\text { Cohen's } \\
\text { D }\end{array}$ \\
\hline Intercept & $\begin{array}{l}4.313 * * * \\
(.039)\end{array}$ & & $\begin{array}{l}4.54 * * * \\
(.038)\end{array}$ & & $\begin{array}{l}4.638 * * * \\
(.039)\end{array}$ & \\
\hline Turnout & $\begin{array}{l}.369 * * * \\
(.028)\end{array}$ & .442 & $\begin{array}{l}0.386^{* * * *} \\
(.028)\end{array}$ & .321 & $\begin{array}{l}.439 * * * \\
(.030)\end{array}$ & .365 \\
\hline $\begin{array}{l}\text { Participants' } \\
\text { representativeness }\end{array}$ & $\begin{array}{l}.495 * * * \\
(.034)\end{array}$ & .398 & $\begin{array}{l}0.367 * * * \\
(.034)\end{array}$ & .305 & $\begin{array}{l}.416^{* * * *} \\
(.035)\end{array}$ & .35 \\
\hline $\begin{array}{l}\text { Turnout*participa } \\
\text { nts' } \\
\text { representativeness }\end{array}$ & $\begin{array}{l}.005 \\
(.029)\end{array}$ & .004 & $\begin{array}{l}-.043 \\
(.028)\end{array}$ & .036 & $\begin{array}{l}-.006 \\
(.028)\end{array}$ & .005 \\
\hline $\begin{array}{l}\text { Adjusted } \mathbf{R}^{2} \\
\text { F-statistic } \\
\text { Effective } n\end{array}$ & \multicolumn{2}{|c|}{$\begin{array}{c}116.60 * * * \\
1424\end{array}$} & \multicolumn{2}{|c|}{$\begin{array}{c}116.60 * * * \\
1424\end{array}$} & \multicolumn{2}{|c|}{$\begin{array}{c}116.60 * * * \\
1424\end{array}$} \\
\hline
\end{tabular}

